This item was submitted to Loughborough's Institutional Repository (https://dspace.lboro.ac.uk/) by the author and is made available under the following Creative Commons Licence conditions.

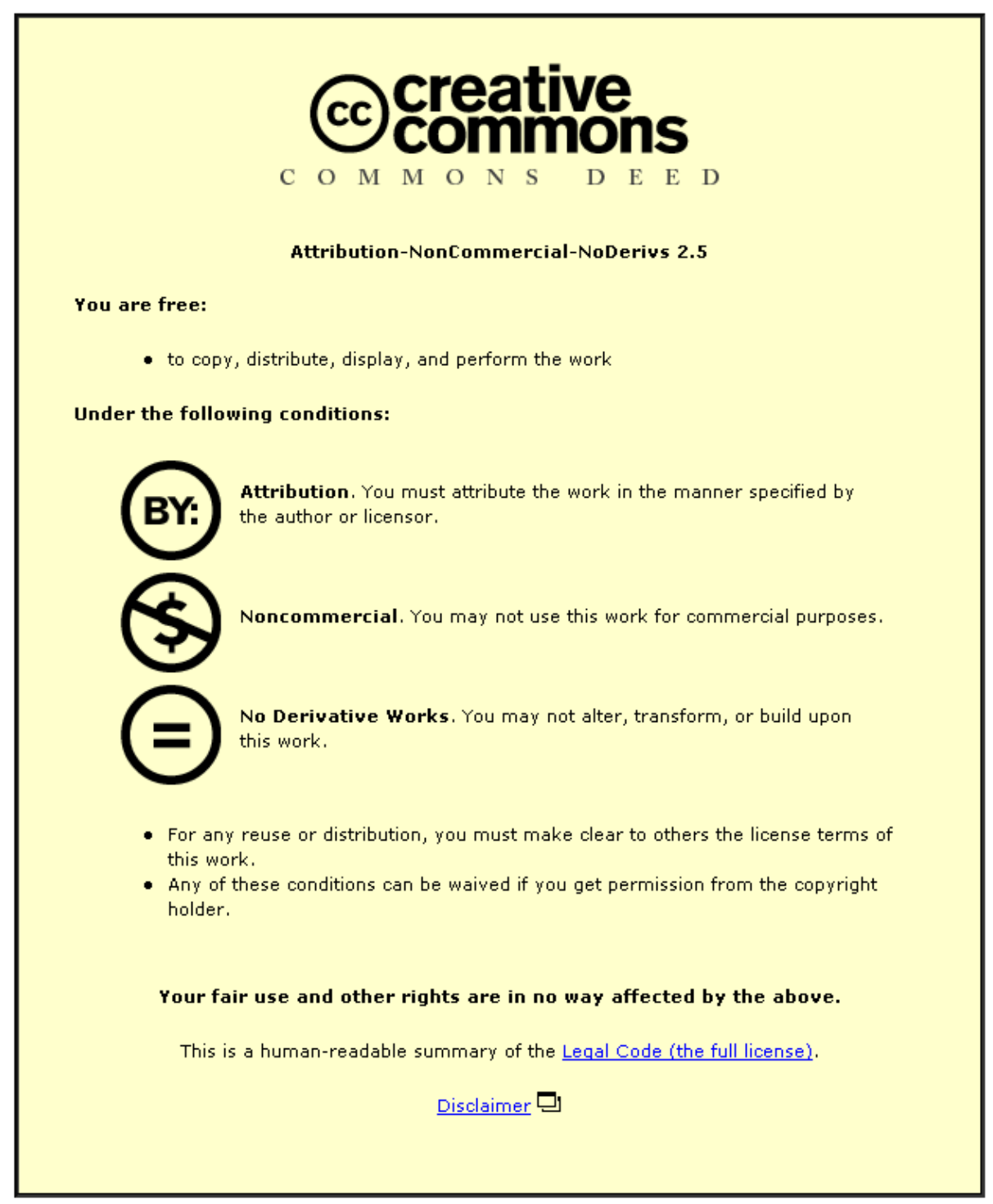

For the full text of this licence, please go to: http://creativecommons.org/licenses/by-nc-nd/2.5/ 
Itoya, Hazell, Ison, El-Hamalawi and Frost

\title{
FRAMEWORK FOR CARBON EMISSIONS EVALUATION OF ROAD MAINTENANCE
}

\author{
Emioshor Itoya, Katrina Hazell, Stephen Ison, Ashraf El-Hamalawi and Matthew
} W. Frost

Currently in the UK, carbon emissions associated with businesses activities has moved from policy requirements to definitive legal responsibilities following the UK's Climate Change Act (CCA) in 2008. Real and pressing need exists for a flexible and easy to use technique to enable businesses to assess their carbon emissions; following recent changes in legislation and regulations on environmental impacts of construction activities. The aim of this paper is to develop a methodology that can offer businesses a carbon Life Cycle Assessment (LCA) tool to identify emissions "hotspots" across its value chain, and inform a carbon reduction hierarchy.

The approach employed is based on the methodology described in the Publicly Available Specification (PAS2050) protocol. The objective of the method is to identify where the largest production of emissions exists and provides for the biggest potential reduction within routine highway maintenance processes. The developed methodology framework offers businesses the potential to make informed decisions in carbon terms, by identifying and prioritizing areas of potential emissions reduction.

Emioshor Itoya, Balfour Beatty Living Places Limited and Loughborough University School of Civil and Building Engineering, Loughborough University, Loughborough, UK, $+44(0) 1256400400$

Emioshor.Itoya@bblivingplaces.com

Katrina Hazell, Balfour Beatty Living Places Limited, Ashwood Park, Ashwood Way, Basingstoke, RG23 8BG, Hampshire, UK. +44(0)1256 400341

Katrina.Hazell@bblivingplaces.com

Stephen Ison, School of Civil and Building Engineering, Loughborough University, Loughborough, UK. +44(0)1509 222605. s.g.ison@lboro.ac.uk

Ashraf El-Hamalawi, School of Civil and Building Engineering, Loughborough University, Loughborough, UK. +44(0)1509 223206. a.el-hamalawi@lboro.ac.uk

Matthew W. Frost, School of Civil and Building Engineering, Loughborough University, Loughborough, UK. +44(0)1509 228306. m.w.frost@lboro.ac.uk. Corresponding author: M. Frost, m.w.frost@lboro.ac.uk.

Words 5472 Tables $2 \quad$ Figures $6 \quad$ Total $5472+2000=7472$ 
Itoya, Hazell, Ison, El-Hamalawi and Frost

\section{INTRODUCTION}

There is a growing consensus that human activities contribute significantly to the increasing concentration of carbon emissions in the atmosphere. These activities cover both individual and industrial activities and their associated energy use $(1,2)$. This has raised a greater awareness and understanding of the environment, and has also called for a change in energy use and other activities that emit carbon; to ensure that future economic development is achieved within economic, social and environmental limits. This is reflected in the UK by a legislative commitment to reduce Greenhouse Gas production (GHG) by at least 80\% by 2050 from 1990 levels $(1,3)$. This places legal obligations on all sectors (including construction) to reduce their emissions, and defines strategies to meet this obligation. Reducing carbon emissions in construction processes is highly desirable given their impact.

Furthermore, carbon emissions reduction is now becoming a contractual requirement and a major consideration in tender selection in both the UK and internationally, particularly for public sector clients. This emerging Key Performance Indicator (KPI) for new projects has placed the construction industry under pressure, particularly the civil infrastructure maintenance sector, to assess and reduce emissions. In the past, businesses wanting to assess their emissions have usually done so by focusing on activities under their immediate control, but recently, customers have required businesses to assess their emissions across their value chain. This is driven by the increasing demand for low-carbon goods and services, and the need to make costeffective investment decisions in carbon terms. The broader strategy by which this demand can be met in construction reach deep into every aspect of the built environment. This presents the construction industry with great business opportunities as well as challenges not simply in terms of immediate business opportunities, but also on long term business standing. The shift in the emissions assessment paradigm promotes the emissions Life Cycle Assessment (LCA) approach that will allow businesses to make an informed decision on emissions reduction.

The Innovation and Growth Team (IGT) - (a team drawn from across the UK's construction industry and public sector) was commissioned by the Department for Business, Innovation and Skills (BIS) to undertake a strategic review of the UK's construction industry and its capacity to rise to the challenge of the low carbon agenda. Key conclusions from the review suggested that the development of a new construction design paradigm supported by new carbon evaluation tools/methodologies that can account for emissions across the construction supply chain is essential (4). The lack of accurate construction emissions inventories, consistent methodology and relevant industrial data have thus been seen as a key challenge to developing any robust carbon emission evaluation methodology (4).

The need to adequately meet legal and clients' requirements, and other broader issues around energy, and materials efficiency in construction to deliver low-carbon services is a long term but pressing issue, and there is a need to develop an emissions LCA methodology that can inform cost-effective investment decisions on emissions reduction. A review of the existing carbon emissions assessment methodologies demonstrate that there is little or no evidence that such an overarching methodology exists within the civil infrastructure maintenance sector. Therefore, the purpose of this paper is to develop a framework methodology that can offer a Life Cycle Assessment (LCA) technique to identify areas of emissions "hotspots" and opportunities for carbon reduction and inform a reduction hierarchy. A LCA methodology based on the Publicly Available Specification (PAS2050) standard is presented. The methodology is specific to road maintenance (e.g. Road Resurfacing). 
Itoya, Hazell, Ison, El-Hamalawi and Frost

This paper provides a literature review, scope, definitions and system boundaries for the life cycle emissions assessment study, and subsequent development of the integrated methodology based on the British PAS2050 standard (an independent standard) specific to civil infrastructure maintenance. A case study is undertaken to demonstrate the implementation of the methodology, using data collected from road resurfacing schemes carried out in an urban environment. Although, emphasis within the paper is on civil infrastructure maintenance services delivery processes, the methodological approach can also be applied in other sectors within the built environment for emissions assessment purposes.

\section{PRIOR STUDIES ON EMISSIONS ASSESSMENT METHODOLOGIES}

Previous studies on construction emissions inventories have been on construction materials and waste management. This was primarily due to the growing debate on materials efficiency (5). Currently, in the UK's construction sector, the methodology commonly used to estimate materials embodied carbon is the Inventory of Carbon and Energy (ICE) methodology produced by Bath University (UK) in collaboration with the Carbon Trust (3, 6, 7). The approach defines a material's embodied carbon as an estimated value of the quantity of emissions expressed in $\mathrm{kgCO}_{2} \mathrm{e}$ per $\mathrm{kg}$ of the material, associated with raw materials extraction; processing and manufacturing, and transportation. The methodology promotes a life cycle emissions assessment technique with boundary conditions consistent with 'Cradle-to-gate'”. The inventory introduces data sets that can estimate embodied carbon associated with construction materials used in the UK. Researchers however believe that the data sets need review with specific data; if the outputs are to be relied upon within the construction industry $(7,8)$.

A number of complementary inventory studies have been conducted to develop construction vehicle and equipment emission inventories over their duty cycle. These include the works by Lewis et al (2009) and Rasdorf et al (2009) (9, 10), aimed at developing a methodology for construction vehicles emissions inventory that can inform a reduction strategy. Although, the methodology provides foundational standard procedures for capturing fuel use by construction fleets and management strategy to inform emissions reduction decisions, the methodology excludes emissions data from materials suppliers; thus failing to promote the full emissions LCA approach.

The UK government and industry-led initiative "Strategy for Sustainable Construction" has set targets to reduce emissions from construction activities by $15 \%$ compared to 2008 by 2012, and reduce all construction and demolition waste sent to landfill by 50\% by 2012, compared to 2005 levels, and zero waste to landfill by 2020 (11). To contribute towards meeting these targets, the Strategic Forum for Construction (SFfC) commissioned a carbon subgroup in 2010 to undertake a study and develop an action plan for emissions reduction from construction activities and associated transport.

The study primarily focused on emissions associated with: On-site activities and accommodation, transportation and corporate offices (12), but said nothing on emissions associated with construction materials, waste management and project owners/user. However, these emissions categories are fundamental to the ideals of a true and accurate LCA emissions assessment. Other contributing works to meeting these targets include studies by the UK's Waste Resources Action Programme (WRAP), commissioned to promote emissions reduction through the use of recycled and secondary aggregate in construction, and enhance resource efficiency (13). These studies showed that choosing less energy intensive construction techniques, selecting 
Itoya, Hazell, Ison, El-Hamalawi and Frost

sources of aggregates closer to site, opting for green transport, and the use of recycled and secondary aggregates can reduce emissions, whilst conserving natural resources and minimizing waste $(3,7,14)$. An extended WRAP LCA emissions assessment methodology has been developed by Thomas et al (15) to assess construction materials sourcing options in carbon terms, and evaluate the emissions impact of previously unconsidered factors such as materials quality and local conditions (e.g. road transport congestion) in the initial WRAP methodology. The study revealed emissions from construction materials sourcing do not only depend on material type, but also local conditions (15). This conclusion concurred with the outcome of a life cycle study conducted in Finland by Mroueh et al (16) on road construction materials characterization; which indicates that construction materials production and transportation produces the most significant environmental burden.

A review of existing studies on life cycle emissions assessment methodologies demonstrates that complexities exist in business emissions assessment. These complexities are further compounded following issues around emissions allocations; lack of robust methodologies and relevant industrial data, and the insufficient analytical rigor showed by the above studies to support businesses in making an informed decision and develop an emissions management strategy across the supply chain. However, the existing studies do indicate that the use of more sustainable practices and materials in the construction process and products has a profound impact on emissions reductions.

The Publicly Available Specification (PAS2050) LCA methodology standard developed by the British Standard Institute (BSI) in 2008; in collaboration with the Department for Environment, Food and Rural Affairs (DEFRA) and the Carbon Trust has shown sufficient analytical rigor to address the above complexities associated with business emissions assessment. (17). It's robustness is inherent in the significant inputs received from international stakeholders, experts across academia, businesses, government and non-governmental organizations (NGOs), through formal consultations and multiple technical working groups (17). The approach has been tested through diverse business streams and has proved to be robust. To widely integrate this LCA concept into construction processes and its value chain, the development of a new and integrated emissions assessment methodology framework within construction is imperative; this paper now presents the framework development process based on this PAS2050 LCA and its application in road maintenance works in an urban environment.

\section{THE FRAMEWORK DEVELOPMENT PROCESS}

This section presents the background to PAS2050 standard, the LCA methodology framework and scope definitions and system boundaries. The three stages and five basic steps to implement the LCA methodology framework defined in Figure 1 are further discussed.

\section{Background to PAS2050}

PAS2050 was developed by British Standard Institute (BSI) $(18,19)$. to produce a consistent and robust method of assessing life cycle emissions for goods and services. It forms an independent standard enhancing methods created in the ISO14040 and ISO14044 LCA protocols (18).

It offers an iterative process where the scope and objectives of the assessment are defined, relevant data are collected these are analyzed and interpreted within the scope and system boundary and data quality defined by the standard. 
Itoya, Hazell, Ison, El-Hamalawi and Frost

\section{The Methodology Framework}

The framework presented is divided into the life cycle stages and an iterative three stage process. The life cycle stages help users to define and build a representative process map for emissions assessment, while the iterative element (Start-up, Service emissions calculation and Results) defines and outlines the five steps to enable the service to be evaluated in carbon terms. Figure 1 presents the LCA methodology framework developed which is specific to civil infrastructure maintenance operations (particularly for highways).

\section{Scope Definitions and System Boundaries within the Model}

Defining system boundaries and the scope of emissions assessment have been key challenges when developing emission frameworks. Within the PAS2050 approach, these challenges have been addressed through the definition of two types of model for LCA studies, namely: the Business-to-Customer (B2C) model - where the customer is the end user of the product (this model is consistent with the "Cradle-to-Grave" boundary condition), and the Business-toBusiness (B2B) model - where the customer is another business using the product as input into its own process. This model is consistent with the "Cradle-to-Gate" boundary condition (17). The application of PAS2050 LCA methodology to both models in service emissions assessment covers both direct and indirect emissions which include embodied, operational and end-of-life carbon emissions.

The embodied carbon defines the energy consumed in raw material extraction, transportation to the factory, the product manufacturing process and transportation to the customer's gate (B2C model). Operational carbon category defines the energy consumed (e.g. fossil fuel) by operatives travel and site operations. While the end-of-life carbon accounts for the energy consumed during waste transportation, processing and recycling. The summation of these carbon emissions categories from a life cycle perspective is referred to as the service Carbon Footprint (CF).

\section{Stage One: Start-up within the Framework}

\section{Step 1}

Setting Service Objectives - Defining and agreeing specific objectives prior to commencing the emissions assessment agenda can create direction with respect to the scope, boundaries and data required for assessment (17). Adequate stakeholder engagement is imperative to define the objectives, processes to be assessed, data type required, data collection and a programme of action.

Selecting Core Highway Processes - Core highways maintenance and management processes can be selected across various locations for emissions assessment. These include: road resurfacing works, bulk lamp/lantern change, line marking, patching and grass cutting/ litter picking.

Engaging Stakeholders - Adequate stakeholder engagement is crucial to understanding business service emissions and the interface that exist between the service and its supply chains. Conventionally, a stakeholder (internal and external) engagement plan is required early to define 
Itoya, Hazell, Ison, El-Hamalawi and Frost

objectives, scope, expected business benefits and allocate responsibilities to enhance the data collection process and address issues around safety/legal/commercial confidentialities.

\section{Step 2}

Developing Data Collection Templates and Schedule - Both quantitative and qualitative data collection templates are useful to ensure a consistent and formalized data collection approach. The quantitative templates should focus on data around site locations, materials inputs and suppliers, fuel consumed by vehicles and equipment, (during waste processing and recycling), while the qualitative templates should focus on capturing expert's opinions on the emissions agenda within the context of their day-to-day jobs. This data set can be used as a basis to compare and justify results. Prior to site data collection, it is crucial to assure those involved of the following:

- Data collection procedures will not interrupt the daily operatives’ productivity.

- Number of site visits per process per location should be specified and agreed.

- Site safety rules and requirements will be obeyed.

Operatives - Site operative's cooperation will help with the daily site specific information particularly on materials inputs; waste generated and amount of fuel consumed on site per scheme.

\section{Stage Two: Service Emissions Calculations}

\section{Step 3: Building Process Map, and Review Boundaries and Priorities}

The aim of this phase is to identify all processes, activities, tasks and associated data inputs that are relevant to undertake emissions assessment in life cycle terms. To model complex scenarios of real-world problems, the Integrated Definition Language (IDEF0) and process decomposition techniques are employed (20). These techniques are employed within this paper, and involve breaking down selected business processes into levels of granularity, where the lower-levels define corresponding upper-level processes (21). Road resurfacing was selected as an example; as part of a wider study to produce carbon emissions inventory for routine highway works. This activity was divided into its life cycle stages, activities and tasks levels in order to evaluate its emissions in life cycle terms. The embodied, operational and end-of-life carbon categories were estimated, which help to identify areas of emissions hotspots across the predefined boundary condition (Cradle to end-of-life). Figure 2 below presents the road resurfacing process map that fits the framework defined in Figure 1.

The process map is structured into three different levels, expected outputs and boundary conditions.

- Level One: Outlines the life cycle stages for the selected service process (road resurfacing work) to enable a full emissions life cycle assessment to be undertaken.

- Levels Two and Three: Defines the various activities and tasks relevant to assess the life cycle stages in carbon terms. Level two indicates the activity-oriented data to evaluate the various emissions categories (Embodied carbon, Operational carbon and End-of-life carbon), while level three allows the expected emissions outputs of the 
Itoya, Hazell, Ison, El-Hamalawi and Frost

emissions categories to be analyzed to identify areas of emissions hotspots across the road resurfacing process value chain.

- The expected emissions outputs and boundary conditions define the emissions assessment results and the boundary conditions that underpin the assessment.

\section{Step 4: Data Type, Collection Procedures and Quality Assurance Measures}

The PAS2050 emissions assessment approach recommends that primary activities data and emission factors are required to calculate the service or product Carbon Footprint (CF) (17). Within this case study, data, in its appropriate units in terms of materials used (one kilogram of material) and fuel (liters) consumed by vehicles (for both outgoing and return journey), site equipment, waste processing and the recycling process were collected.

The scale of work undertaken was measured directly on site and the design specification of material types identified. The total daily materials deliveries and distance covered from the manufacturing plant; including return journey were obtained from the suppliers' delivery tickets. Figure 3 presents an approach that enables the daily amount of fuel consumed to be accurately measured. Site waste transfer notes provide information on total waste (planings) generated on site in tonnes, and distance covered from site to recycling plant including return journey. These data sets were entered into the quantitative data templates and later transferred into an Excel Spreadsheet. Material manufacturers and waste recycling companies provided information on the embodied energy and carbon associated with materials manufacture, their delivery to customer's gates, and energy use for waste processing and recycling.

Fuel-based emission factors were selected from publicly available emission factors databases $(7,20)$.

During field data collection, measures were taken to ensure PAS2050 data quality rules are met with concern given to their completeness, consistency, reproducibility and source (18), whist minimizing data errors such that:

- The recorded volume of materials (e.g. asphalt) used on site were compared with the quantities from contract documents and invoices.

- Materials manufacturers were allowed to collect primary data, and estimate their embodied carbon based on the quantity of material supplied to site.

- For limited cases where operatives failed to follow the data collection approach presented in figure 3, particularly site fuel usage; such operations were excluded from the data collection exercise.

- Accompanying each data sets are the names of the road maintenance schemes, site locations and nature of work undertaken.

\section{Step 5: Data Analysis}

Equations 1, 2 and 3 can be employed to calculate embodied, operational and end-of-life carbon emissions associated with construction activities.

Embodied carbon $(\Phi)=\sum_{i=1}^{i=w}[\mathrm{E}] i w \times \mu$

Operational carbon $(\Omega)=\sum_{j=1}^{j=n}[\mathrm{H}] j n \times \lambda$ 
Itoya, Hazell, Ison, El-Hamalawi and Frost

End-of-Life carbon $(\Psi)=\sum_{k=1}^{k=z}[\Pi] k z \times \lambda$

Total Carbon Footprint $(C F)=(\Phi)+(\Omega)+(\Psi)$

$\sum[\mathrm{E}]=$ Sum of $\boldsymbol{i}^{\text {th }}$ energy consumed during raw materials acquisitions, materials manufacturing, transportation to $w^{\text {th }}$ customers gates.

$\mu$ : The appropriate emission factors from publicly available databases.

$\sum[\mathrm{H}]=$ Sum of total energy consumed by $n^{\text {th }}$ equipments and vehicles during their duty

cycle on $j^{\text {th }}$ sites.

$\lambda$ : The appropriate emission factors from publicly available databases.

$\sum[\Pi]=$ Sum of total energy consumed to transport, processed and recycled $z^{\text {th }}$ tonnes of waste generated from $k$ sites.

$(C F)$ : The sum of emissions categories outputs. This represents the total Carbon Footprint (CF) per project.

\section{CASE STUDY: ROAD MAINTENANCE WORKS}

As part of the framework development and improvement a case study was undertaken. The aim was to demonstrate industrial implementation of the methodology developed. Four road resurfacing schemes of different areas and site locations were selected in an urban environment to allow comparability of emissions assessed and identify where emissions hotspots exist within the highway routine maintenance process. The road resurfacing activities within the four schemes included: planing-off of existing road surfaces to a nominal depth of $100 \mathrm{~mm}$ and reinstating the planed surfaces with a thin layer of tack coat (K140), 60mm AC 20 HDM BIN40/60 DES binder course and 40mm surface course. Table 1 provides a brief overview of the selected road maintenance schemes, the nature and scale of work undertaken.

\section{Data Analysis}

To ensure clarity of results associated with the case study data analysis, two analyses modes were developed: the activity-oriented and task-oriented mode. The activity-oriented mode defines the Embodied Carbon, Operational Carbon and End-of-Life Carbon, and the taskoriented mode defines asphalt production and transportation to the customers' gate, operatives travel, site operations, waste transport off-site, waste processing and recycling. (see Figure 2). By using equations 1, 2 and 3, (above) emissions were evaluated quantitatively in terms of carbon. The fuel-based emission factors selected from the publicly available databases (2.6720 $\mathrm{kgCO}_{2} \mathrm{e}$ per liter and $2.71780 \mathrm{kgCO}_{2} \mathrm{e}$ per $\mathrm{kg}$ ) were used to convert the primary data (e.g. tonnes of materials and waste, liters of fuel consumed) into their corresponding kilogram of 
Itoya, Hazell, Ison, El-Hamalawi and Frost

carbon dioxide equivalent, expressed in $\operatorname{kgCO}_{2} \mathrm{e}(7,22)$ Fuel-based emission factors were selected instead of time-based emission factors since they are less sensitive to site variables (23). A sensitivity analysis was further undertaken during the case study to identify relevant exploratory variables for emission rates that can inform emissions reduction decisions. Variables identified were material haulage distance to site (miles), congestion, and number of deliveries to site, average distance travelled by operatives (miles) and scale of work undertaken. This approach allowed emission hotspots to be identified within the case study in terms of life cycle and associated opportunities for a reduction to inform a reduction hierarchy

\section{RESULTS AND DISCUSSION}

In terms of the four roads maintenance schemes based on the framework methodology developed the results are summarized into the activity-oriented mode analysis, task-oriented mode analysis and exploratory analysis (sensitivity).

\section{Activity-Oriented Data Analysis}

This analytical approach allows the embodied carbon, operational carbon and end-of-Life carbon associated with the four schemes to be estimated. Site activities and tasks carbon emissions analyses are presented in Table 2. The percentage averages of each activity-oriented mode compared to the overall Carbon Footprint (CF) is presented in Table 2a. These results indicate that materials embodied carbon accounts for on average $79.08 \%$ of the total CF, irrespective of the scale of work undertaken and material supplier, whilst operational carbon and end-of-life carbon accounts for an average of $13.36 \%$ and $7.56 \%$ respectively. These results suggest that embodied carbon value is not just a function of the material type (quality), but also materials quantity, haulage distance and local conditions (e.g. consequential congestion).

\section{Task-Oriented Data Analysis}

The task-oriented analysis approach allows the road scheme activities emissions to be further analyzed to identify areas of emissions hotspots that can inform the emissions reduction decision and prioritized reduction efforts. Asphalt production was found to account on average for $98 \%$ of the total materials embodied carbon and its transportation with other materials accounting for the $2 \%$ of the embodied carbon. Analysis of Table $2 \mathrm{~b}$ reveals that asphalt production accounts for 75\%, Site operations: $8.4 \%$, waste transportation: $6.9 \%$, operatives travel: $5 \%$, asphalt delivery: $4 \%$, waste processing and recycling (into secondary aggregate) produces $0.7 \%$ respectively compared to the schemes total Carbon Footprint (CF): $27538 \mathrm{kgCO}_{2} \mathrm{e}$. These results confirm the key findings of Durucan and Korre's (14) LCA study on road construction materials characterization; which conclude that construction materials production and transportation produces the most significant environmental burden.

\section{Exploratory Analysis}

An interpretation of the case study results indicate that there is a significant increase in emission rates per mile travelled for vehicles carrying load (e.g. Delivering materials or equipment to sites) compared to vehicles not carrying a load. This increase in emission rates is attributable to 
Itoya, Hazell, Ison, El-Hamalawi and Frost

the fuel type (diesel) used to estimate the schemes transport emissions. Diesel produces a significant increase in emission rates at high engine combustion rates due to loading and congestion.

Table 2c shows that an increase in emission rates has a significant correlation with an increase in distance to site, materials haulage distance and numbers of material deliveries to site, particularly in an urban environment. This correlation is primarily due to the fuel type (diesel) used for the emissions assessment and the impact of congestion. For example, the asphalt delivery to site and waste transport off-site produces emission rates of an average of $19.1 \mathrm{kgCO}_{2} \mathrm{e} /$ trip and $23.9 \mathrm{kgCO}_{2} \mathrm{e} / \mathrm{mile}$ for a mile increase in distance between sites, and $0.003 \mathrm{kgCO}_{2} \mathrm{e}$ per tonne of asphalt per mile and $0.0823 \mathrm{kgCO}_{2} \mathrm{e}$ per tonne of waste transported off site, while operatives' travel produces average emission rates of $9.84 \mathrm{kgCO}_{2} \mathrm{e} / \mathrm{mile}$ for an average distance (128miles) travelled.

These results tally with key conclusions from Thomas et al (2009) LCA study (15) which aimed to assess aggregates sourcing options. It revealed that emissions associated with construction materials sourcing do not only depend on material type, but also local working conditions. In addition to the above examples. Figures $4 \mathrm{a} \& 4 \mathrm{~b}$ reveal that emission rates associated with construction material delivery or waste transportation off site, increases with an increase in distance between site and material manufacturing plant, and waste recycling facilities and the site. Further exploratory analysis on the scale of work impact on site operations emission rates, in Table 2c reveals that road planing emission rates (average of $0.268 \mathrm{kgCO}_{2} \mathrm{e} / \mathrm{m}^{2}$ and $1962 \mathrm{~m}^{2}$ ) increases as expected; with an increase in the scale of work (increase in areas and depth of road surfaced planed).

\section{Carbon Emissions Reduction Hierarchy}

Detailed assessment of the data analyses and discussions above provide the basis upon which the carbon emissions reduction hierarchy in Figure 5 is developed. The hierarchy of reduction is expected to provide road designers, managers and planners the knowledge framework to support emissions reduction investment decision-making, and enable efforts to be prioritized. The emissions reduction hierarchy presented in this paper is specific to road resurfacing work carried out in an urban environment. The order of priority - where to focus emissions reduction efforts may change slightly if a similar scale of work is carried out in a different environment (such as rural or semi-urban location).

\section{CONCLUSIONS AND RECOMMENDATIONS}

This paper has presented the development of a framework based on LCA methodology described in PAS2050. Although, the application of the framework methodology developed in this paper relates to road maintenance, the approach can also be used for other highway construction schemes so as to identify areas of emissions hotpots and develop a reduction hierarchy.

This study has aimed to address significant gaps in the current body of knowledge in relation to business emissions assessment methodology. It presents a methodology that can provide the civil infrastructure maintenance sector with a LCA tool to assess their business environmental performance to inform decision-making across its whole value chain in turn. To enhance comparability of emissions assessed, the area of emissions hotspots and associated 
Itoya, Hazell, Ison, El-Hamalawi and Frost

emissions reduction hierarchy for four road maintenance schemes carried out in an urban location have been presented.

The process map developed allows the activity-oriented and task-oriented emissions modes to be evaluated. The case study results reveal the methodology has the potential to identify areas of emissions hotspots, and opportunities for reduction. It offers a robust tool that can allow businesses to accurately understand their carbon expenditure, and inform an emissions reduction strategy to enhance their competitiveness. The case study reveals that asphalt production, site operations, waste transportation, operatives travel and asphalt delivery are areas of maximum carbon usage, and important aspects in sustainability decisions for road designers, managers and maintainers, to enable them to priorities emissions reduction.

Energy efficiency in material production, selecting less energy intensive construction methods and adequate site logistic planning are critical for highway maintenance to meet both environmental and business risks, and opportunities to manage competitiveness in a "carbon conscious” business environment.

Recommendations below are informed following the experience gained during the site data collection. These include:

- An effective business stakeholder engagement strategy to develop a representative process map to support field data collection, and allow businesses to accurately understand the emissions interfaces that exist between the businesses and avoid double carbon emissions accounting.

- To adequately improve site carbon emission data gathering, it is crucial to allocate responsibilities across the business value chain to prevent data quality problems, and ensure that representative emissions data are collected to build a robust emissions information for business sustainable procurement decision-making.

- Emission factors convert measured and estimated quantities (data) into their corresponding emissions value. Fuel-based emission factors are recommended where available for process emissions evaluation. These factors are less sensitive to site variability compared to time-based emission factors.

\section{REFERENCES}

1. United Kingdom. Food and Rural Affairs Department for Environment. The UK Climate Change Act, 2008. http://www.opsi.gov.uk/acts/acts2008/pdf/ukpga_20080027_en.pdf . Accessed Dec. 21, 2008.

2. Dlugolecki A. The Carbon Disclosure Project : the Tyndall Centre for Climate Change ,London, 2003.

3. Transport Research Laboratory Limited. .WRAP project MRF136. $\mathrm{CO}_{2}$ estimator tool for aggregate : User Guide v2.0 2010.

http://www.wrap.org.uk/downloads/The_CO2_emissions_estimator_tool_for_the_use_of_ag gregates_in_construction___User_Guide_v2.0.8574693b.9125.pdf. Accessed Feb. 2011

4. United Kingdom. Innovation and Skills Department for Business. Low Carbon

Construction, Final Report, 2010.http://www.bis.gov.uk/assets/biscore/businesssectors/docs/1/10-1266-low-carbon-construction-igt-final-report.pdf. Accessed Feb. 2011

5. Waddell H. Sustainable Construction and UK Legislation and Policy. Proceedings of the Institution of Civil Engineers : Management, Procurement and Law, 2008, Vol.161, No.3, pp. 127-132. 
Itoya, Hazell, Ison, El-Hamalawi and Frost

6. Hammond G. P., and C.I. Jones. Embodied Energy and Carbon in Construction Materials. Proceedings of the Institution of Civil Engineers: Energy, 2008, Vol. 161, No. EN2, pp. 8798.

7. Hammond G. P., and C.I. Jones. Inventory of Carbon and Energy (ICE). Sustainable Energy Research Team (SERT). University of Bath, United Kingdom, 2011. (accessed 14/07/2011).

8. New Civil Engineer. Low Carbon: Building a better future, 2009. http://www.nce.co.uk/lowcarbon-building-a-better-future/5208913.article. Accessed Feb.2011.

9. Lewis P., H.C.Frey, and W.J.Rasdorf. Development and Use of Emissions Inventories for Construction Vehicles. In Transportation Research Record: Journal of the Transportation Research Board, No.2123, Transportation Research Board of the National Academies, Washington, D. C., 2009, pp. 46-53.

10. Rasdorf W., P. Lewis, H.C.Frey. Estimating Productivity Emission Rates and Cost Emission Rates of Diesel Construction Equipment. Proc., of the $6^{\text {th }}$ International Conference on Innovation in Architecture, Engineering and Construction (AEC), Pennsylvania State University, United States, Jun. 2009.

11. United Kingdom. Enterprise and Regulatory Reform Department for Business. Strategy for Sustainable Construction, 2008. http://www.berr.gov.uk/files/file46535.pdf . Accessed Nov. 17, 2009.

12. Joan K. Carbon: Reducing the Footprint of Construction Process. - an Action Plan to Reduce Carbon Emissions, Strategic Forum for Construction and Carbon Trust, 2010. http://www.nscc.org.uk/documents/StrategicForumCarbonActionPlan.pdf . Accessed Nov. 2010

13. United Kingdom. Waste Resource Action Programme. Environmental Benefits of Recycling. .Final Report, 2010.

http://www.wrap.org.uk/downloads/Environmental_benefits_of_recycling_2010_update.f78 d8063.8816.pdf. Accessed Oct. 2010

14. Durucan S., and Korre, A. Life Cycle Assessment of Aggregates Imperial College London, 2009.

http://www.wrap.org.uk/downloads/Life_Cycle_Assesment_of_Aggregates_User_Guide.86 7908a8.8878.pdf . Accessed March, 2011

15. Thomas A., D. R. Lombardi, D. Hurt and M. Gaterell. Estimating Carbon dioxide Emissions for Aggregate Use. Proceedings of the Institution of Civil Engineers: Engineering Sustainability, 2009, Vol. 162, No. 3, pp. 135-144.

16. Mroueh U. M., P. Eskola and J. Laine-Ylijoki. Life-Cycle Impacts of the use of Industrial by-products in Road and Earth Construction .Journal of Waste Management, 2001, Vol. 21, No. 3, pp. 271-277.

17. British Standards Institute. Publicly Available Specification (PAS2050). How to Assess the Carbon Footprint of Goods and Services: Guide to PAS2050, London, 2008. http://www.bsigroup.com/upload/Standards\%20\&\%20Publications/Energy/PAS2050Guide.pdf. Accessed Jun. 2009

18. British Standards Institute. Publicly Available Specification (PAS2050). Specification for the Assessment of the Life Cycle Greenhouse gas emissions of goods and services: New revision, London, 2011. http://www.bsigroup.com/upload/Standards\%20\&\%20Publications/Energy/PAS2050.pdf .Accessed Oct. 2011 
Itoya, Hazell, Ison, El-Hamalawi and Frost

19. Sustain Limited. PAS2050 Briefing Document. UK, 2010. http://www.sustain.co.uk/resources/briefing-documents-and-reports/pas2050-briefingdocument.aspx Accessed Feb. 2011

20. Koskela L. Application of the New Production Philosophy to Construction. .Technical Report No. 72 Centre for Integrated Facility Engineering, Stanford University, United States, 1992.

21. Cooper R., G. Aouad, A. Lee, S. Wu, A.Fleming and M. Kagioglou. Process Management in Design and Construction, Technical and Technologies for Managing the Product Development Process in Construction, Blackwall Publishing, Oxford, 2005, p. 29.

22. United Kingdom. Food and Rural Affairs/Department of Energy and Climate Change Department for Environment. The 2010 Guidelines to DEFRA/DECC's Greenhouse Gases Conversion Factors for Company Reporting, 2010.http://archive.defra.gov.uk/environment/business/reporting/pdf/101006-guidelinesghg-conversion-factors.pdf. Accessed Jan. 2011

23. Frey H. C., W. J. Rasdorf, K. Kim, S. Pang and P. Lewis. Comparison of Real World Emissions of Beckholes, Front-End Loaders, and Motor Graders for B20 Biodiesel versus Petroleum Diesel and For Selected Engine Tiers. In Transportation Research Record: Journal of the Transportation Research Board, No.2058, Transportation Research Board of the National Academies, Washington, D. C., 2008, pp. 33 - 44. 
Itoya, Hazell, Ison, El-Hamalawi and Frost

FIGURE 1 LCA methodology framework to evaluate road maintenance emissions inventory

FIGURE 2 Process map for road resurfacing operation

FIGURE 3 Field data collection methodology flowchart

FIGURE 4(a) Transport emission rate for asphalt delivery to site

FIGURE 4(b) Transport emission rates for waste transport off-site

FIGURE 5 Emissions reduction hierarchy for road maintenance in an urban location 
Itoya, Hazell, Ison, El-Hamalawi and Frost

TABLE 1 Brief Overview of Selected Road Maintenance Schemes

TABLE 2 Analyses of Site Activities and Tasks Carbon Emissions

TABLE 2(a) Analysis of Activity-oriented Mode Contribution to Road Maintenance Total Carbon Footprint (CF)

TABLE 2(b) Task-oriented Mode Analysis to Identify Areas of Significant Emissions

TABLE 2(c) Evaluations of Emission Rates Associated with Task-oriented Mode 
Itoya, Hazell, Ison, El-Hamalawi and Frost

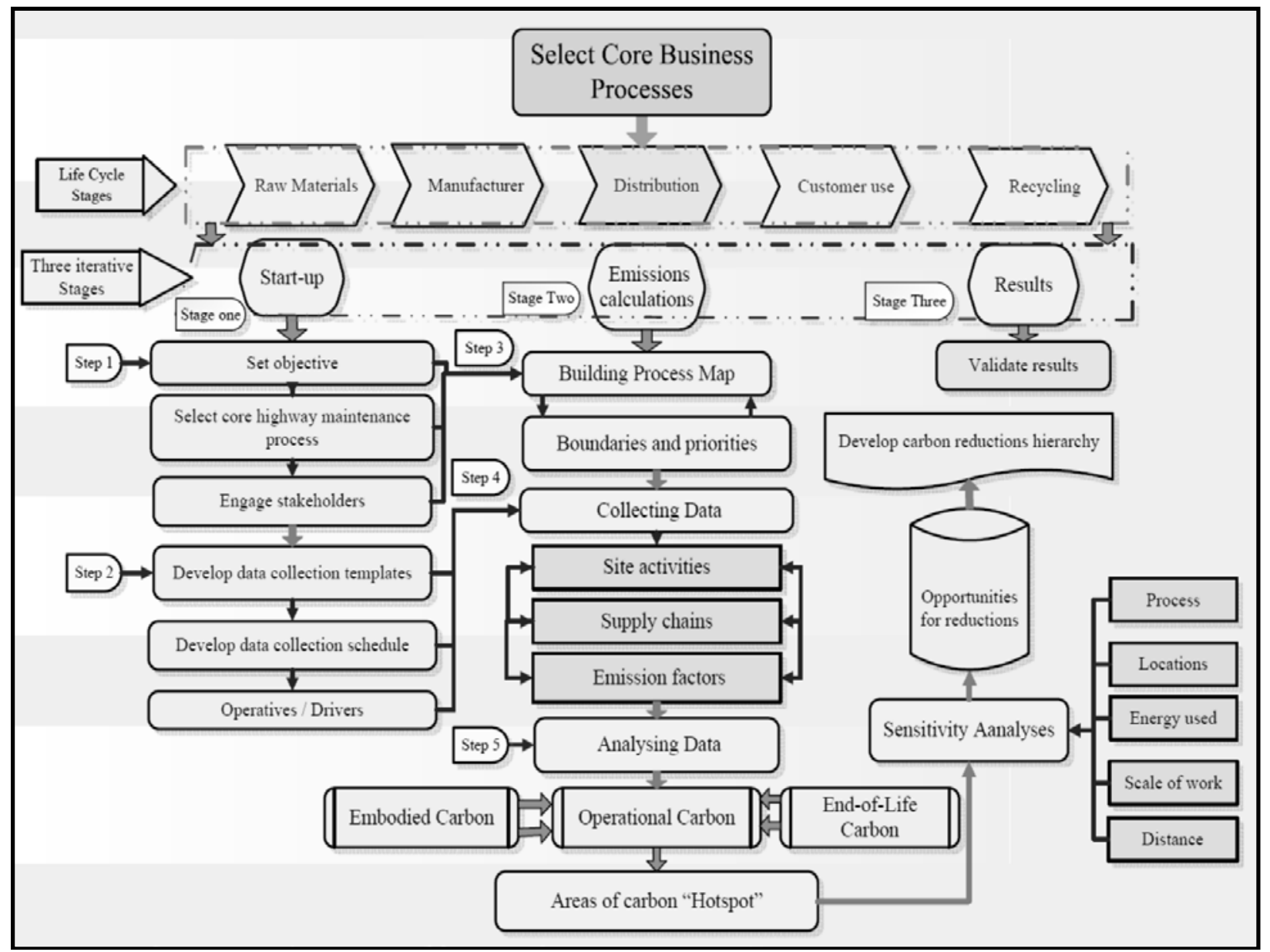

FIGURE 1 LCA methodology framework to evaluate road maintenance emissions inventory 
Itoya, Hazell, Ison, El-Hamalawi and Frost

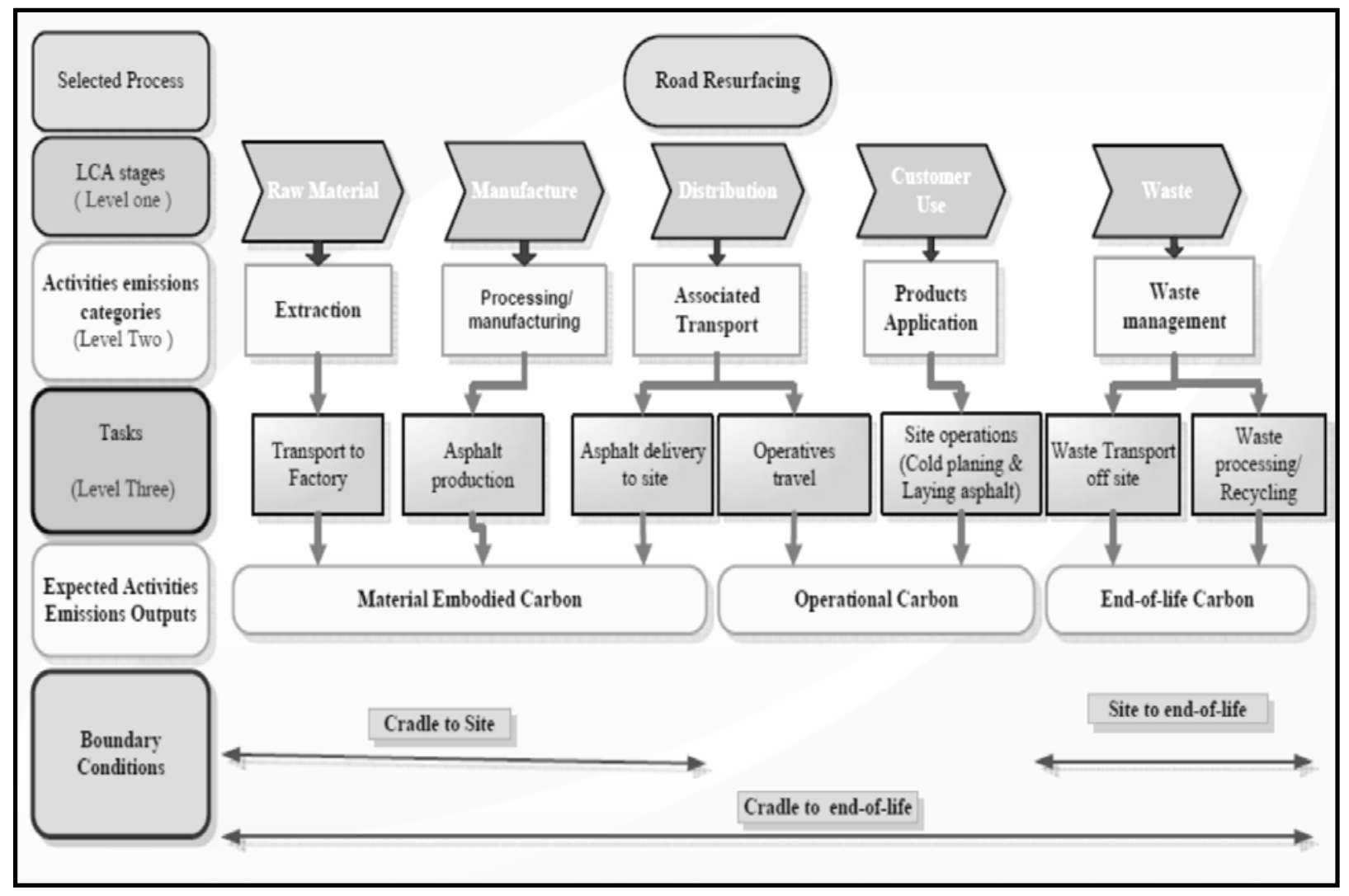

FIGURE 2 Process map for road resurfacing operation 
Itoya, Hazell, Ison, El-Hamalawi and Frost

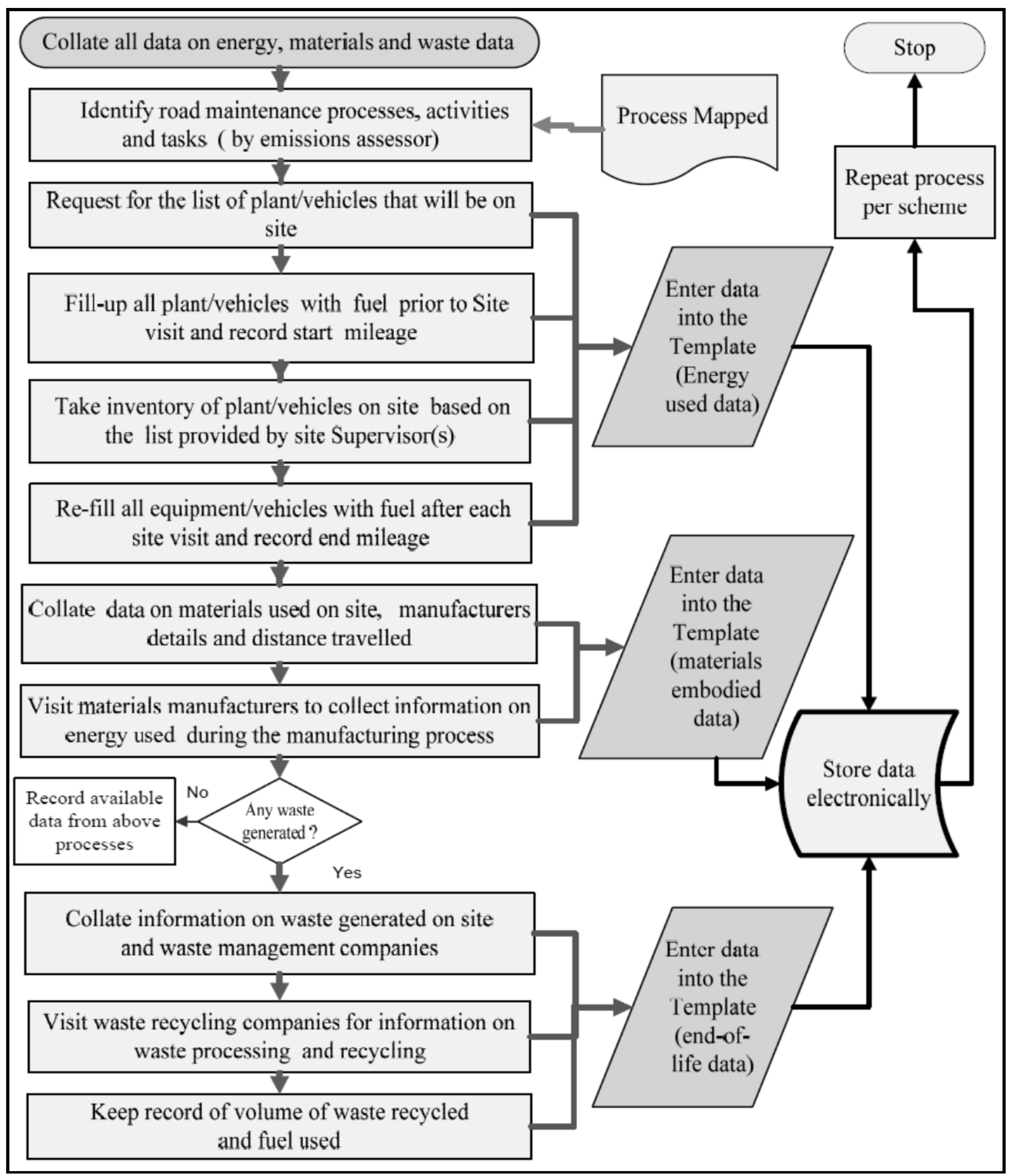

FIGURE 3 Field data collection methodology flowchart 
Itoya, Hazell, Ison, El-Hamalawi and Frost

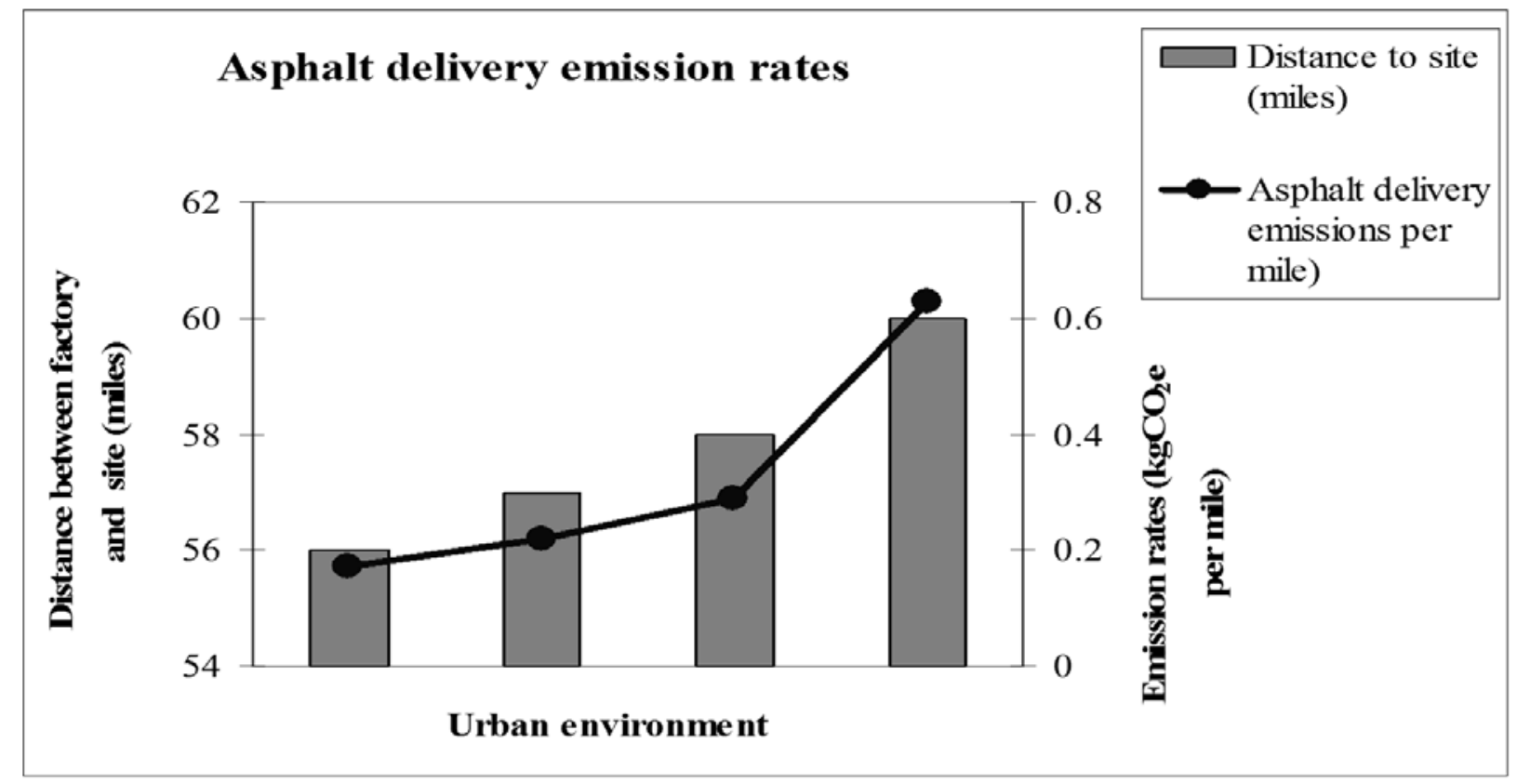

FIGURE (4a) Transport emission rate for asphalt delivery to site 
Itoya, Hazell, Ison, El-Hamalawi and Frost



FIGURE 4(b) Transport emission rates for waste transport off-site 
Itoya, Hazell, Ison, El-Hamalawi and Frost

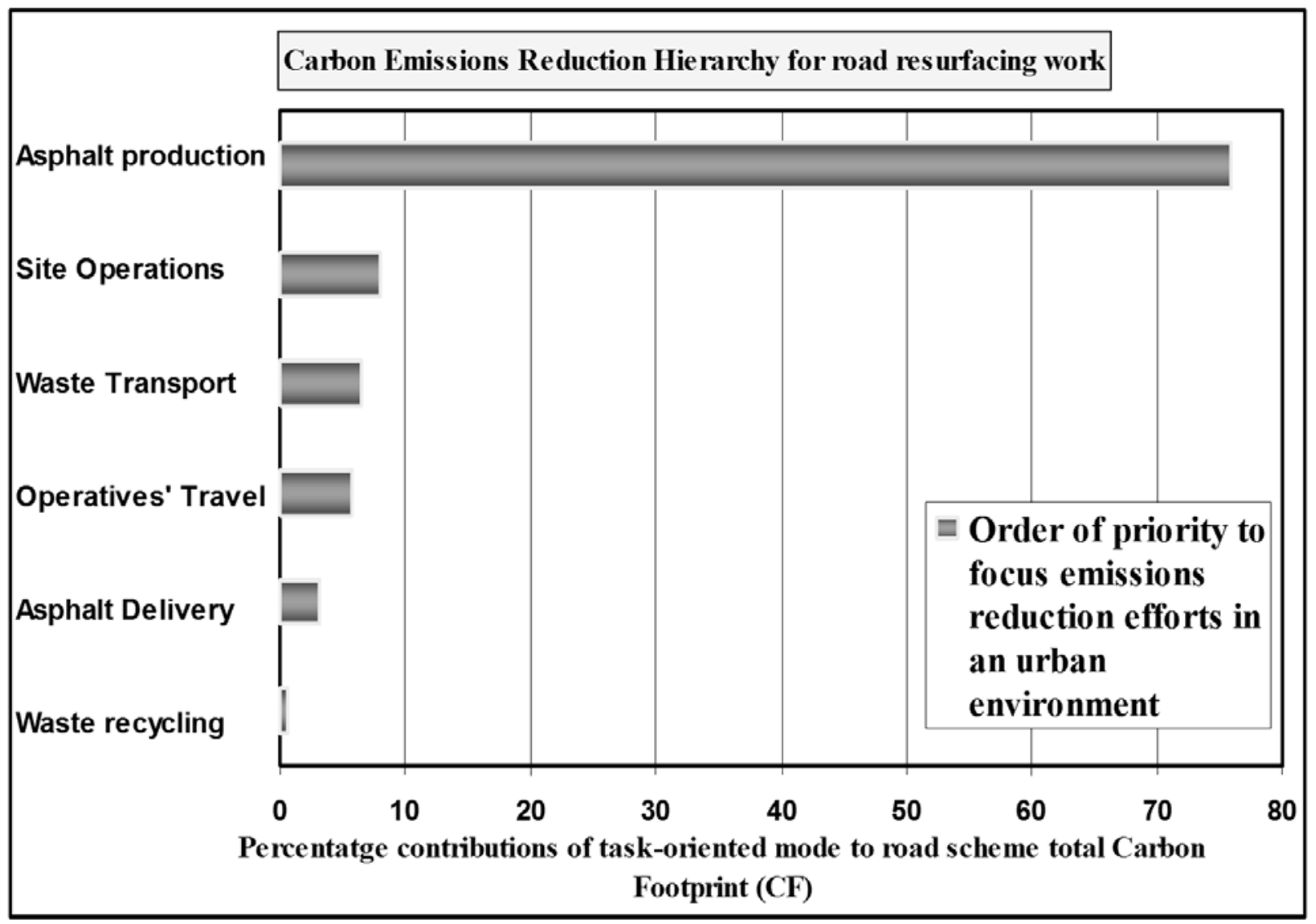

FIGURE 5 Emissions reduction hierarchy for road maintenance in an urban location 
Itoya, Hazell, Ison, El-Hamalawi and Frost

TABLE 1 Brief Overview of Selected Road Maintenance Schemes

\begin{tabular}{|c|c|c|c|c|c|c|c|c|c|}
\hline Location & Nature of work & $\begin{array}{c}\text { Depth } \\
(\mathrm{mm})\end{array}$ & $\begin{array}{c}\text { Total } \\
\text { area } \\
\left(\mathrm{m}^{2}\right)\end{array}$ & $\begin{array}{c}\text { Quantity } \\
\text { of } \\
\text { Asphalt } \\
\text { (tonnes) }\end{array}$ & $\begin{array}{c}\text { Distance } \\
\text { to site (a } \\
\text { trip) } \\
\text { (miles) }\end{array}$ & $\begin{array}{c}\text { Number } \\
\text { of trip } \\
(19.99 \\
\text { tonnes } \\
\text { per trip) }\end{array}$ & $\begin{array}{c}\text { Quantity } \\
\text { of Tack } \\
\text { Coat } \\
\text { K140 } \\
\text { (Litres) }\end{array}$ & $\begin{array}{c}\text { Quantity } \\
\text { of } \\
\text { Polymer } \\
\text { Modified } \\
\text { Bitumen } \\
\text { (kg) }\end{array}$ & $\begin{array}{c}\text { Total } \\
\text { Waste } \\
\text { generated } \\
\text { (tonnes) }\end{array}$ \\
\hline \multirow{4}{*}{ Urban } & Deep Planing/inlay & $100 / 40$ & 2945 & 758 & 60 & 38 & 2062 & 200 & 600 \\
\hline & Deep Planing & 100 & 2593 & 294 & 58 & 15 & 1493 & 125 & 220 \\
\hline & Deep Planing & 100 & 1284 & 290 & 57 & 15 & 642 & 25 & 195 \\
\hline & Deep Planing/inlay & $100 / 40$ & 1024 & 237 & 56 & 12 & 512 & 25 & 90 \\
\hline
\end{tabular}


Itoya, Hazell, Ison, El-Hamalawi and Frost

TABLE 2(a) Analysis of Activity-oriented Mode Contribution to Road Maintenance Total Carbon Footprint (CF)

\begin{tabular}{|c|c|c|c|}
\hline & $\therefore$ 我 & & 悬 \\
\hline & $\therefore \underset{\frac{1}{4}}{0}$ & $\begin{array}{l}\infty \\
\stackrel{\infty}{\sim} \\
\stackrel{p}{\sim}\end{array}$ & 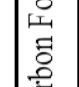 \\
\hline & 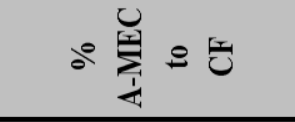 & 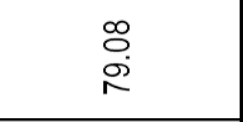 & $\mid \begin{array}{l}\tilde{u} \\
\ddot{u} \\
\ddot{\sigma}\end{array}$ \\
\hline$\frac{\mathrm{U}}{\frac{\mathrm{U}}{\pi}}$ & 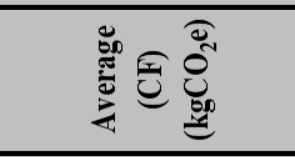 & 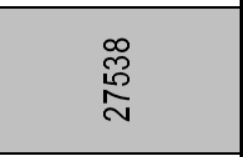 & 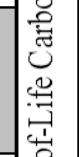 \\
\hline$\frac{0}{\frac{0}{0}}$ & $\mathrm{~A}-\mathrm{ELC}\left(\mathrm{kgCO}_{2} \mathrm{e}\right)$ & @̊ & 害 \\
\hline$\stackrel{\mathscr{\Xi}}{\frac{\mathscr{\omega}}{0}}$ & $\mathrm{~A}-\mathrm{OC}\left(\mathrm{kgCO}_{2} \mathrm{e}\right)$ & $\stackrel{\infty}{\infty}$ & $\mid$ \\
\hline 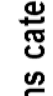 & $\mathrm{A}-\mathrm{MEC}\left(\mathrm{kgCO}_{2} \mathrm{e}\right)$ & 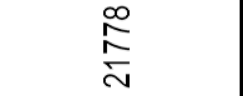 & 岂 \\
\hline 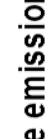 & 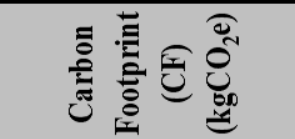 & 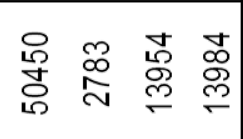 & 总 \\
\hline $\begin{array}{l}\frac{\pi}{\bar{J}} \\
\frac{\mathrm{\omega}}{\mathrm{J}} \\
0\end{array}$ & 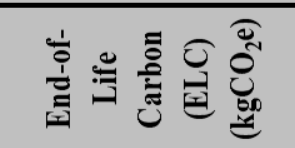 & 옹웡 & 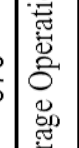 \\
\hline 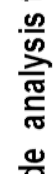 & 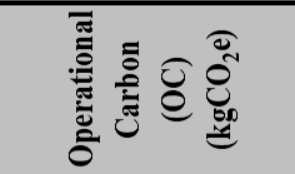 & 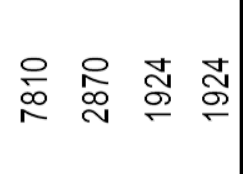 & 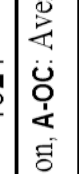 \\
\hline 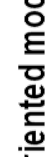 & 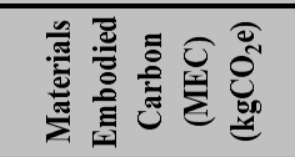 & 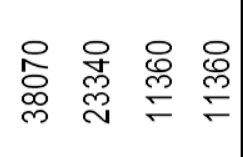 & 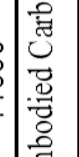 \\
\hline$\sum_{\substack{i\\
}}^{0}$ & 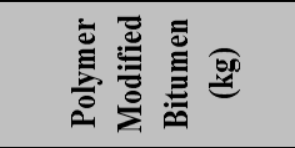 & $\stackrel{\sim}{\stackrel{\sim}{\sim}} \stackrel{\sim}{\sim} \stackrel{\sim}{\sim}$ & 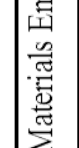 \\
\hline & 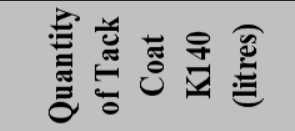 & 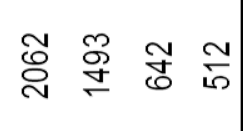 & 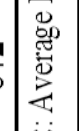 \\
\hline & 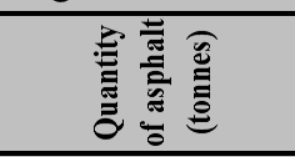 & 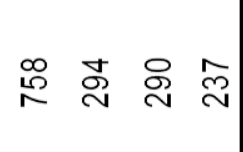 & $\sum_{\dot{4}}^{3}$ \\
\hline & $\overline{\overparen{g}}$ & 导 总 总 & \\
\hline
\end{tabular}


Itoya, Hazell, Ison, El-Hamalawi and Frost

TABLE 2(b) Task-oriented Mode Analysis to Identify Areas of Significant Emissions

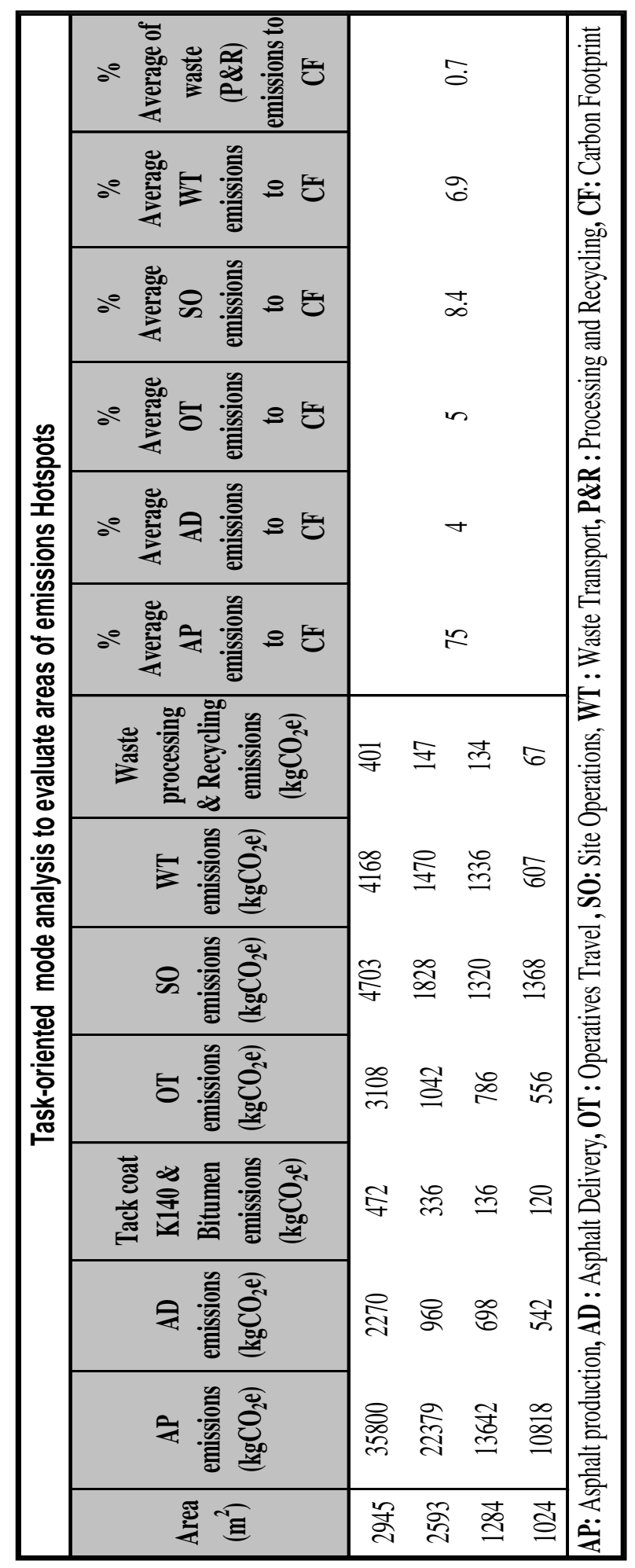


Itoya, Hazell, Ison, El-Hamalawi and Frost

TABLE 2(c) Evaluations of Emission Rates Associated with Task-oriented Mode

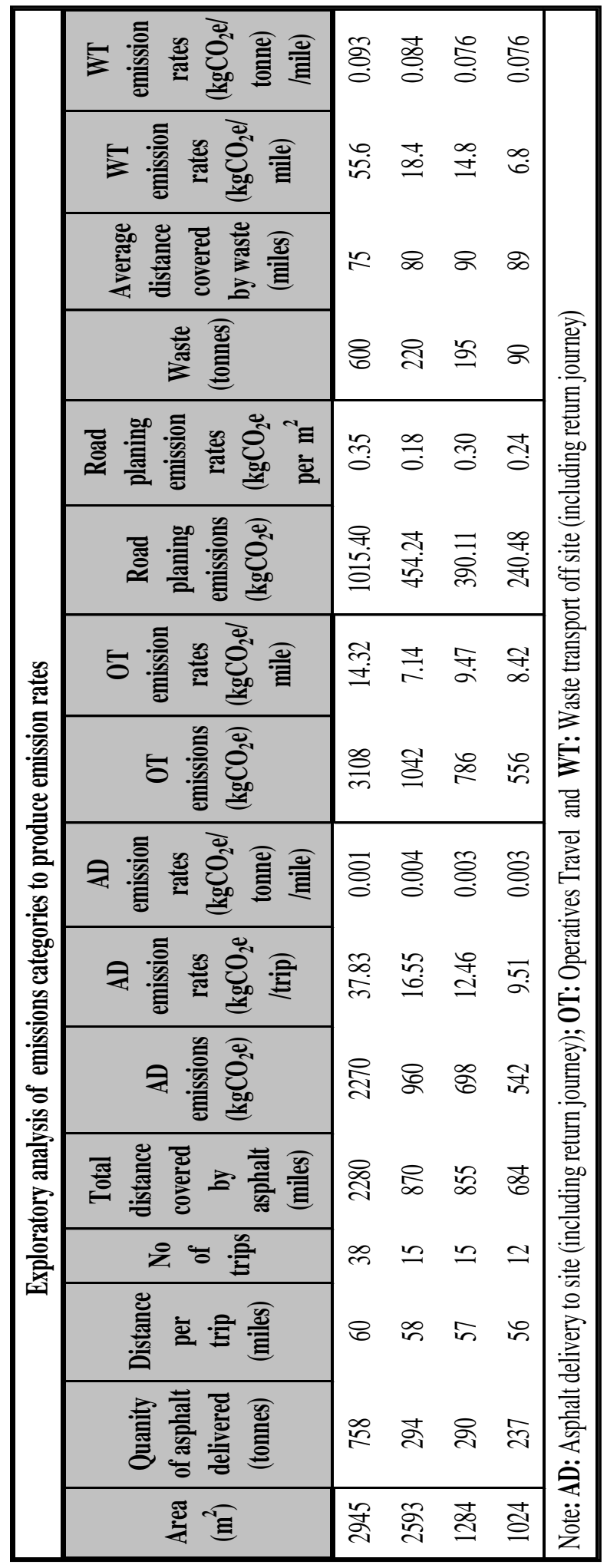

